\title{
Role of melatonin combined with exercise as a switch-like regulator for circadian behavior in advanced osteoarthritic knee
}

\author{
Yunkyung Hong 1,2,3,4, Hyunsoo Kim², Seunghoon Lee ${ }^{1,2,3,4}$, Yunho Jinn 2,3,4, Jeonghyun \\ Choi $^{2,3,4}$, Sang-Rae Lee ${ }^{5}$, Kyu-Tae Chang ${ }^{5}$ and Yonggeun Hong ${ }^{1,2,3,4}$ \\ ${ }^{1}$ Department of Physical Therapy, College of Biomedical Science \& Engineering, Inje University, Gimhae, Korea \\ ${ }^{2}$ Department of Rehabilitation Science, Graduate School of Inje University, Gimhae, Korea \\ ${ }^{3}$ Biohealth Products Research Center (BPRC), Inje University, Gimhae, Korea \\ ${ }^{4}$ Ubiquitous Healthcare \& Anti-aging Research Center (u-HARC), Inje University, Gimhae, Korea \\ ${ }^{5}$ National Primate Research Center (NPRC), Korea Research Institute of Bioscience and Biotechnology (KRIBB), Ochang, \\ Korea \\ Correspondence to: Yonggeun Hong, email: yonghong@inje.ac.kr
}

Kyu-Tae Chang, email: changkt@kribb.re.kr

Keywords: osteoarthritis, metabolic homeostasis, melatonin, exercise, circadian clock

Received: November 01, $2016 \quad$ Accepted: May 12, $2017 \quad$ Published: July 16, 2017

Copyright: Hong et al. This is an open-access article distributed under the terms of the Creative Commons Attribution License 3.0 (CC BY

3.0), which permits unrestricted use, distribution, and reproduction in any medium, provided the original author and source are credited.

\section{ABSTRACT}

Here, we show the role of melatonin combined with or without exercise as a determinant of multicellular behavior in osteoarthritis. We address the relationship between the molecular components governing local circadian clock and changes in the osteoarthritic musculoskeletal axis. Melatonin was injected subcutaneously in animals with advanced knee osteoarthritis (OA) for 4 weeks. Concurrently, moderate treadmill exercise was applied for $\mathbf{3 0} \mathrm{min} /$ day. Morphometric, histological, and gene/proteinlevel analyses were performed in the cartilage, synovium, bone, and gastrocnemius muscle. Primary cultured chondrocytes repeatedly exposed to TNF-a were used in an in vitro study. The symptoms of $O A$ include gait disturbance, osteophyte formation, and abnormal metabolism of the extracellular matrix (ECM) of the cartilage. Lowlevel expression of clock genes was accompanied by aberrant changes in cartilage specimens. Nanomolar doses of melatonin restored the expression of clock-controlled genes and corrected the abnormal chondrocyte phenotype. Melatonin combined with or without exercise prevented periarticular muscle damage as well as cartilage degeneration. But prolonged melatonin administration promoted the proteolytic cleavage of RANKL protein in the synovium, leading to severe subchondral bone erosion. These musculoskeletal changes apparently occurred via the regulation of molecular clock components, suggesting a role of melatonin as a switch-like regulator for the OA phenotype.

\section{INTRODUCTION}

The socioeconomic burdens associated with the care of OA patients is predicted to increase as societies age. Ongoing research seeks to eliminate aberrant chondrocyte behavior, such as hypertrophic differentiation [1], mineralization [2], and calcification [3], but no curative treatment has yet been found. Time-dependent treatment (chronotherapy) has been suggested to be useful in the management of OA patients, in whom daily rhythms of symptoms (i.e., pain, stiffness, and manual dexterity) are evident [4]. Rhythmic gene expression ( $\sim 3.9 \%$ of all expressed genes) controlled by the circadian clock is apparent in cartilage specimens $[5,6]$. The core clock machinery is composed of genes including Clock, Bmall, Per, and Cry [7]. The CLOCK and BMAL1 proteins dimerize to activate transcription of the Per and Cry genes, reciprocal expression of which contributes to 
rhythmic regulation of tissue physiology. The transcription factor Bmall is a well-known pacemaker expressed in many tissues; cartilage-selective Bmall deletion triggered progressive chondral lesions [6]. Tissue-specific clocks are entrained by several cues (i.e., photic stimulation, feeding, and exercise) [8], but both aging and exposure to proinflammatory cytokines induce loss of rhythm.

The pineal hormone melatonin (N-acetyl-5methoxytryptamine) is a potent circadian synchronizer response to photoperiod in the mammals [9]. Melatonin has anti-oxidant and anti-inflammatory properties [10, 11 ], even though it has long been recognized as a diseasepromoting agent in rheumatoid arthritic conditions [12]. However, the pharmacological concentrations $(\mu \mathrm{M}$ to $\mathrm{mM}$ ) can stimulate not only generation of reactive oxygen species (ROS) but also cytokine production [13]. Our preliminary studies confirmed that moderate-intensity exercise can effectively inhibit the phenotypic changes due to prolonged melatonin treatment [14]. Mild-to-moderate exercise suppresses inflammatory processes $[15,16]$ by generating biomechanical stimuli mediated by articular compression [17]. Although circadian regulation of the major genes in the musculoskeletal system is considered to be useful for medication, little information is available about the effect of intervention on the regulation of clock mechanism. Here, we assessed the role of melatonin combined with or without exercise as a determinant of clock-controlled behaviors. Moreover, an inflammatory microenvironment in the joint can cause synovitis [18], bone erosion [19], and perimetric muscular weakness, contributing to functional impediment [20]. Thus, we performed a holistic approach to correct the changes occurred in the OA musculoskeletal axis.

\section{RESULTS}

\section{Melatonin with or without exercise inhibited the metabolic shift toward catabolism in advanced osteoarthritic cartilage}

The anteroposterior thickness of the knee increased in animal with advanced OA (Figure 1A, a). Also, the right-to-left walking distance decreased, indicating that the ability to support the damaged knee was compromised (Figure 1A, b). These changes were accompanied by an increase in the serum TNF- $\alpha$ level (Figure 1A, c), which was slightly lower in the melatonin-treated group, but higher than in the control. The serum TNF- $\alpha$ level was reduced by exercise. The knee thickness returned to nearnormal, similar to that of controls, both experimental groups (Figure 1A, a). However, melatonin treatment alone did not ameliorate the gait disturbance, indicating that the functional impediment persisted (Figure 1A, b). The extent of loading tolerated by the injured limb improved when melatonin treatment and exercise were combined.

Chondrocytes were homogeneously distributed throughout the cartilage in hematoxylin-eosin (H\&E)stained images of the Con group (Figure 1B, a), but images from the vehicle-treated group exhibited the typical histological features of OA (i.e., cleft formation, surface irregularities, and tidemark duplication). Type II collagen protein (COL2A1) was overexpressed in OA cartilage, indicative of a homeostatic imbalance in the matrix (Figure 1B, b). Caspase-3 cleavage was also evident. Four weeks of melatonin treatment partially, but not completely, reduced cartilage damage. Furthermore, the degree of inhibition was greater when melatonin treatment was combined with exercise. Aberrant behaviors of chondrocytes were also observed by real-time qPCR. OA cartilage shows abnormal upregulation of catabolic factors, such as Mmp13, Vegf, and Alp (Figure 1C, c). However, the expression of some anabolic factors (e.g., Tgfß1, Sox9, and Col2a1) was unchanged or suppressed (Figure 1C, b). These pathological changes were accompanied by a marked reduction in expression of the circadian core clock components (Figure 1C, a). The expression of Per 2 and Cryl genes, except Bmall gene, was augmented by melatonin treatment combined with or without exercise, the level of which was higher in the combined group. In particular, combined treatment seemed to maintain the metabolic balance between matrix synthesis and degradation through transcriptional suppression.

\section{Melatonin determined the cellular phenotype during the period of chondrocyte damage}

Primary cultures of chondrocytes were used to assess the effects of melatonin. Caspase-3 cleavage was initiated within 10 min after addition of TNF- $\alpha$ and was sustained for up to $1 \mathrm{~h}$ (Figure 2A, a). Cell viability did not change during this time, but was reduced at $4 \mathrm{~h}$ (Figure 2A, b). Thus, we applied cumulative stress via TNF- $\alpha$ treatment every $4 \mathrm{~h}$. Melatonin increased proportion of viable cells, but the pharmacological dose used $(1 \mathrm{mM})$ retarded cell growth (Figure 2A, c). Both the vehicle and melatonin at $1 \mathrm{mM}$ affected the machinery of the chondrocyte clock (Figure 2B). Vehicle-treated cells showed not only an inconsistency between Bmal1 transcription and translation but also a reduction of Per2 gene expression. Bmall mRNA abundance was consistent with the protein level in $1 \mathrm{mM}$ melatonin-treated cells. This concentration exhibited a reverse pattern between expression of Bmall gene and that of Per2 gene. But 1 $\mathrm{nM}$ melatonin restored the expression level of clock genes.

Pathological features were evident after disruption of clock machinery, including loss of glycosaminoglycans (GAGs) (Figure 2C), MMP-13 activation (Figure 2D, 


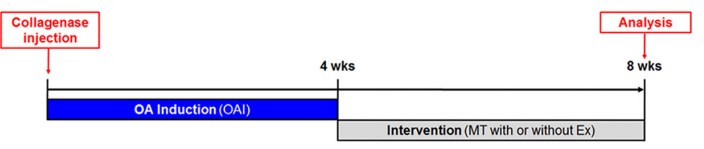

(a)

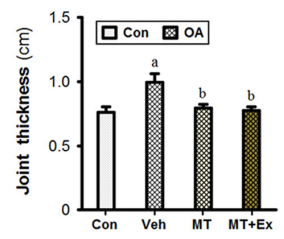

(b)

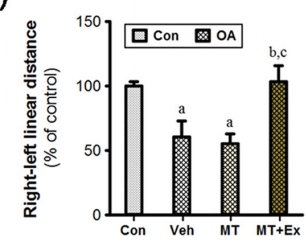

(c)

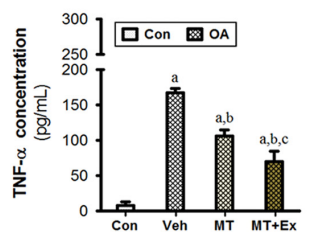

B

(a)

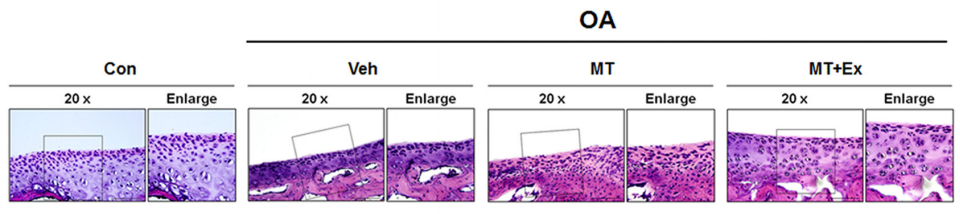

(b)
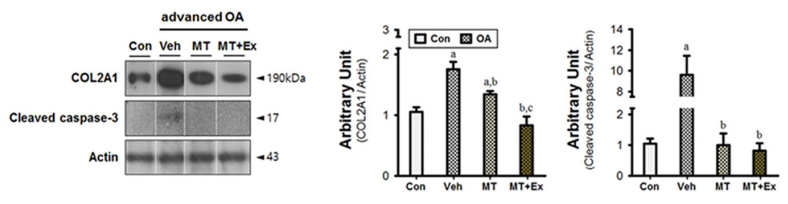

C

(a)

(b)
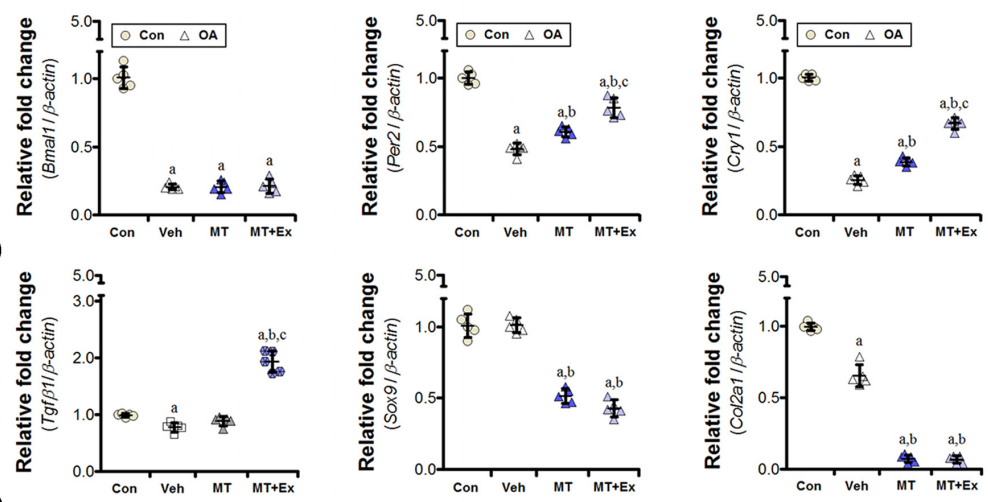

(c)
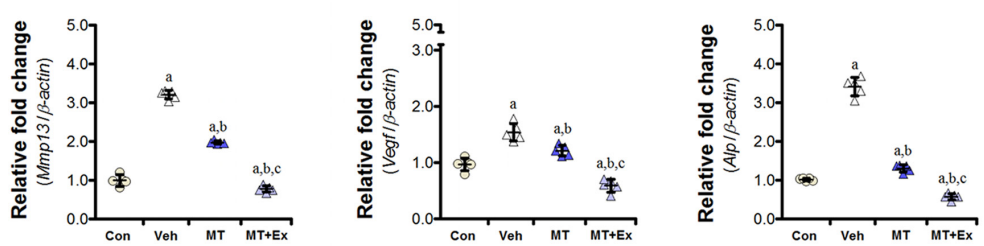

Figure 1: Melatonin combined with exercise restores metabolic balance in osteoarthritic cartilage. A. Collagenase was injected to induce moderate-to-severe knee OA in animals, and the intervention was applied for 4 weeks. (a) Anteroposterior knee thickness was assessed with calipers in anesthetized rats $(n=8)$; the value increased in cases of advanced OA. (b) The right-to-left linear distances ( $n$ $=24$ for each condition) were normalized with the value of the control rats. (c) The concentration of TNF- $\alpha$ present in serum was reduced by the intervention, the degree of which was greater in combination with exercise. B. (a) Co-treatment blocked histological deterioration in the tibial cartilage specimens. Magnification $\times 40$, scale $b a r=100 \mu \mathrm{m}$. (b) Immunoblot to detect the indicated proteins (COL2A1, caspase-3) showed that abnormal metabolic control occurred in the OA cartilage. C. The cartilage specimens were harvested at ZT14. (a) Aberrant expression of genes associated with chondrocyte behavior was accompanied by dysregulation of molecular clock components (Bmall, Per2, and Cry 1). Melatonin with or without exercise maintained the homeostatic balance via the suppression of (b) anabolic (Tgfß1, Sox9, and Col2al) and (c) catabolic (Mmp13, Vegf, and Alp) factors. PCR data were normalized to $\beta$-actin. ${ }^{\mathrm{a}} P<0.05, v s$. Con, ${ }^{\mathrm{b}} P<0.05, v s$. $\mathrm{OA}+\mathrm{Veh},{ }^{\mathrm{c}} P<0.05$, vs. $\mathrm{OA}+\mathrm{MT}$. 
Table 1: Quantitative analysis of osteoarthritic tibiae by micro-CT

\begin{tabular}{|c|c|c|c|c|c|c|c|c|}
\hline & \multicolumn{4}{|c|}{ Medial condyle } & \multicolumn{4}{|c|}{ Lateral condyle } \\
\hline & Con & Veh & MT & $\mathbf{M T}+\mathbf{E x}$ & Con & Veh & MT & $\mathbf{M T}+\mathbf{E x}$ \\
\hline BV/TV (\%) & $34.1 \pm 0.8$ & $30.0 \pm 1.2^{*}$ & $28.7 \pm 1.9^{*}$ & $28.9 \pm 1.6^{*}$ & $14.5 \pm 1.5$ & $15.1 \pm 1.7$ & $12.3 \pm 0.7^{*}$ & $14.4 \pm 1.1$ \\
\hline $\mathrm{P}$-value & \multicolumn{4}{|l|}{0.005} & \multicolumn{4}{|l|}{0.015} \\
\hline Tb. Th $(\mu \mathrm{m})$ & $127.9 \pm 1.2$ & $112.8 \pm 1.5^{*}$ & $114.2 \pm 5.7^{*}$ & $109.4 \pm 0.8^{*}$ & $100.9 \pm 5.0$ & $90.7 \pm 2.7$ & $80.4 \pm 2.3^{*}$ & $100.5 \pm 4.0^{\#}$ \\
\hline P-value & \multicolumn{4}{|l|}{0.001} & \multicolumn{4}{|l|}{0.011} \\
\hline Tb. Sp $(\mu \mathrm{m})$ & $233.4 \pm 7.2$ & $221.6 \pm 6.9^{*}$ & $220.2 \pm 3.3^{*}$ & $232.5 \pm 7.1$ & $278.1 \pm 9.1$ & $281.3 \pm 7.5$ & $275.3 \pm 8.5$ & $280.9 \pm 7.9$ \\
\hline P-value & \multicolumn{4}{|l|}{0.017} & \multicolumn{4}{|l|}{0.852} \\
\hline
\end{tabular}

${ }^{*} \mathrm{P}<0.05$ vs. Con; ${ }^{*} \mathrm{P}<0.05$ vs. $\mathrm{MT}$

a), and upregulation of gene encoding clock-controlled catabolic factors (i.e., Mmp14 and Adamts4/9) (Figure 2D, c). $1 \mathrm{mM}$ melatonin promoted marked activation of MMPs at both the transcriptional and protein levels (Figure 2D, a). But the expression of Adamts genes was unchanged in $1 \mathrm{mM}$ melatonin-treated cells (Figure 2D, c). Deposition of GAGs remained at a decreased level in the $1 \mathrm{mM}$ melatonin-treated group, although the value is higher than that of vehicle-treated cells (Figure 2C). These results indicate high dose melatonin might induce more severe degradation of collagen, rather than proteoglycan. However, abnormal behaviors of chondrocyte were almost recovered by $1 \mathrm{nM}$ melatonin treatment.

We then confirmed MMP-13 localization in inflamed chondrocyte (Figure 2D, b). In the fluorescent images, nuclear MMP-13 was 24.7-fold and 6.2-fold higher in the vehicle- and $1 \mathrm{mM}$ melatonin-treated cells than in the control cells, respectively. Cytoplasmic distribution was also increased in two groups, the degree of which was greater in the $1 \mathrm{mM}$ melatonin-treated cells $(\sim 14.5$-fold of control) than vehicle-treated cells ( $\sim 6.5$-fold). While MMP-13 protein was facilitated translocation to the nucleus in vehicle-treated cells, addition of melatonin to millimolar levels reduced the facilitation of translocation of MMP protein to the nucleus. The level of cytoplasmic protein in cells treated with $1 \mathrm{nM}$ melatonin was lower than that in cells treated with $1 \mathrm{mM}$ melatonin, although the extent of nuclear localization was similar. Thus, we suggest that melatonin dose may be important when seeking to control the chondrocyte phenotype.

\section{Melatonin combined with exercise maintained bone homeostasis in joints with advanced $\mathrm{OA}$}

Although intracellular calcium signaling has an important role in chondrocyte mechano-transduction, it may be associated with pathological features if regulation has failed [21]. From the Alizarin red staining, the quantitative value was higher in the $1 \mathrm{mM}$ melatonintreated group only (Figure 3A, a). And there were several cell types with stronger signal staining in the vehicletreated group. Expression of osteoblastic markers (Runx2 and $A l p$ ) was enhanced in the vehicle-treated cells (Figure $3 \mathrm{~A}, \mathrm{~b}$ ), the result of which appeared to be periarticular osteophytes in vivo (Figure 3B). The soluble RANKL (sRANKL):OPG ratio decreased in the synovium of vehicle-treated animals (Figure 3C, a), indicating that the intra-articular environment favored bone formation. The inflammatory environment inhibited cytonuclear shuttling of both PER1 and PER2 (Figure 3C, b), which failed to cause degradation of the BMAL1 protein.

In melatonin-treated cells, the level of RANKL protein, an essential mediator of bone resorption via regulation of osteoclastic activity, was consistently high (Figure 3A, c). We found no significant difference in the RANKL protein levels of cells treated with $1 \mathrm{mM}$ and 1 $\mathrm{nM}$ melatonin, indicating that the resorptive capacity was preserved under inflammatory conditions. Subchondral bone erosion was marked in melatonin-treated animals (Figure 3B). Quantitative micro-CT revealed that the subchondral bones of the medial tibia became damaged under arthritic conditions, regardless of intervention (Table 1). However, the subchondral trabeculae of the lateral epicondyles became thinned when melatonin treatment was prolonged. Also, the relative bone volume (the $\mathrm{BV} /$ TV ratio) decreased in the melatonin-treated group. Microfractures with thin trabeculae were also observed, and the synovial sRANKL:OPG ratio was approximately eight-fold that of the control (Figure 3C, a). The melatonin treatment also altered regulation of the clock proteins, as observed in the vehicle-treated group (Figure 3C, b). The combined intervention corrected these abnormal remodeling processes via recovery of the molecular clock, leading to a reduction in periarticular bony defects. 
A

(a)

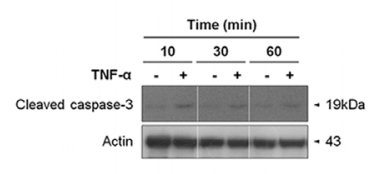

B

(a)

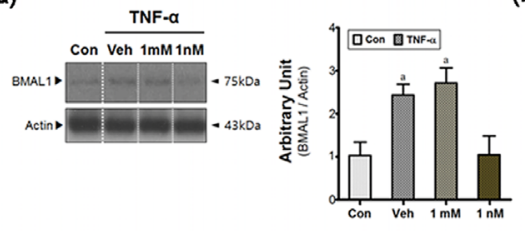

(b)

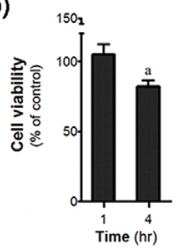

(c)

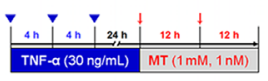

(b)

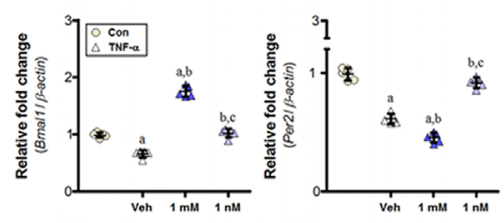

C
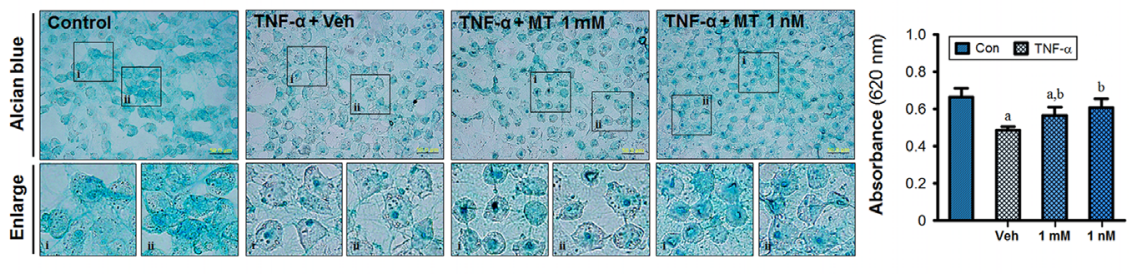

D

(a)

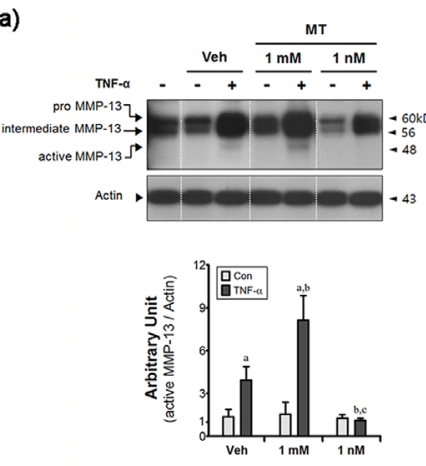

(b)
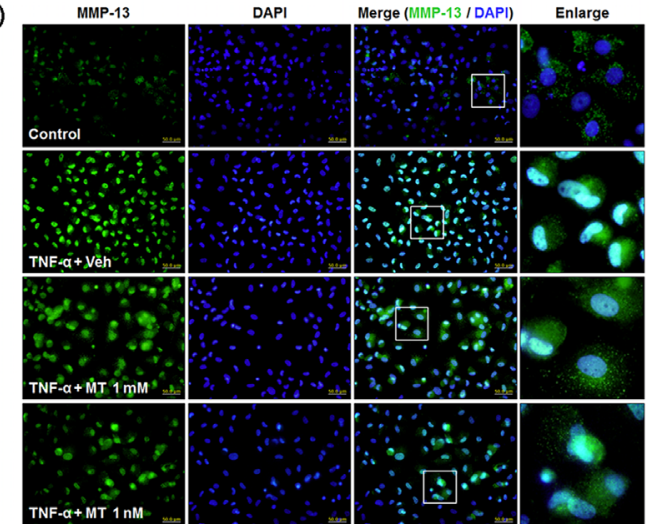

(c)
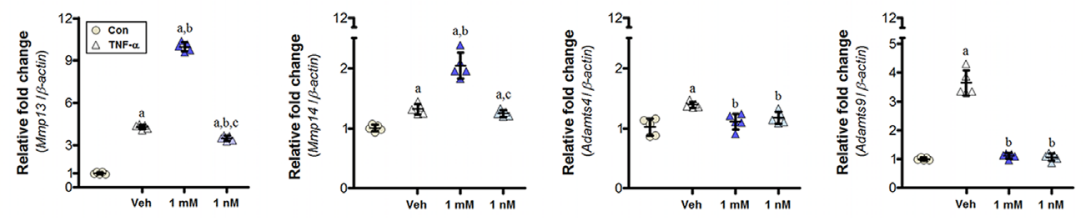

Figure 2: Melatonin determines the cellular phenotype during the period of chondrocyte damage. A. Primary cultures of chondrocytes $\left(5 \times 10^{4} /\right.$ plate) were synchronized via serum shock and treated with recombinant TNF- $\alpha(10 \mathrm{ng} / \mathrm{mL})$. (a-b) single dose of TNF- $\alpha$ sustained the damage response for $4 \mathrm{~h}$. (c) Cell viability was reduced by cumulative inflammatory stress (inverted triangle) and the total cell number decreased in the $1 \mathrm{mM}$ melatonin-treated cells. B. (a) An inflammatory load abnormally altered the BMAL1 protein level in synchronized cells; millimolar melatonin treatment did not rescue this change. (b) Core clock genes (i.e., Bmal1, Per2) were differentially expressed in both groups, but remarkable changes were evident upon treatment with $1 \mathrm{nM}$ melatonin. This triggered dysregulation of both the clock and clock-controlled molecules, in turn impairing rhythmic activities. C. Alcian blue staining was used to assess the amount of glycosaminoglycans (GAGs). Deposition was higher in the melatonin-treated cells, the degree of which was greater in the $1 \mathrm{nM}$ melatonintreated group. Magnification $\times 40$, scale bars $=50 \mu \mathrm{m}$. D. (a) Western blots indicate levels of MMP-13, and its intracellular distribution was determined by (b) immunofluorescence. Nanomolar melatonin treatment inhibited not only proteolytic processing of MMP-13 but also its nuclear localization. Magnification $\times 40$, scale bars $=50 \mu \mathrm{m}$. (c) The expression of clock-controlled catabolic genes (Mmp14, Adamts4/9) was measured by real-time qPCR. Data were normalized to $\beta$-actin. ${ }^{\mathrm{a}} P<0.05$, vs. Con, ${ }^{\mathrm{b}} P<0.05, v s$. DMSO-Veh, ${ }^{\mathrm{c}} P<0.05$, vs. $1 \mathrm{mM} \mathrm{MT}$. 


\section{Melatonin treatment with or without exercise were effective for prevention of indirect muscle damage}

The ipsilateral medial gastrocnemius initiated the adaptive processes in response to load variation on the injured limb. The muscular clock components were dysregulated at both gene and protein level, similar to that in other joint tissues (Figure 4A). Compared with the control group, the levels of circadian clock proteins (CLOCK, BMAL1, and nuclear PER2) were significantly lower in the vehicle-treated group (Figure 4A, a). Additionally, Per 2 expression was suppressed also (Figure $4 \mathrm{~A}, \mathrm{~b})$. Dysregulation of the molecular clock components decreased the abundance of muscle-specific transcripts markedly. For example, myosin heavy chain IIB protein, encoded by the Myh4 gene, represents a large proportion of the medial gastrocnemius [22]; its expression was downregulated (Figure 4B). However, the muscle-specific clock-controlled gene Myhl was unchanged. Melatonin treatment restored the core clock mechanism, similar to the control; this effect was enhanced when exercise was co-applied (Figure 4A). In particular, the expression of Per 2 was 4-fold higher in the melatonin combined with exercise group. A similar trend was observed with the myogenic factors Myod and Myog (Figure 4B).

Based on these findings, we suggest that melatonin combined with exercise could efficiently prevent phenotypic alterations in the moderately-to-severe OA musculoskeletal axis, the mechanism(s) of which may be mediated by regulation of circadian clock molecules in joint tissues.

\section{DISCUSSION}

Previously, we reported that circulating TNF- $\alpha$ increased $\sim 5.5$-fold in rats with early ongoing OA [14]. Its level was higher in the present study than the previous result because of elapsed time, equivalent to 8 weeks, which leads to the more advanced OA-like phenotype [23]. This is important because the interventional effect depends on the status at the starting point [24]. TNF- $\alpha$ in culture medium initiated the damage response, and cumulative stress induced hypertrophic changes in primary cultured cells, similar to the animal results. This was accompanied by reductions in not only Bmall and Per 2 gene expression, suggesting that the molecular clock components in chondrocytes are dysregulated during $\mathrm{OA}$ progression.

The circadian rhythm can be synchronized in several ways (e.g., by the light/dark cycle or a rest/activity cycle, by exercise, and by feeding times); the output rhythms affect many physiological and behavioral variables (i.e., melatonin secretion, the sleep/wake cycle, and the core body temperature). Mechanical stimuli (e.g., the daily rest/activity cycle and exercise) are major synchronizers of the musculoskeletal clock. The effects of exercise on melatonin secretion have been extensively reported [2528]. Thus, we explored the effect of melatonin on the maintenance of musculoskeletal physiology. Rhythmic expression of the canonical clock genes (i.e., Bmall, Per2) governing metabolic homeostasis was identified in mouse cartilage [5]. Moreover, a loss of circadian rhythmicity in the Bmall-null mice induces age-dependent arthropathy [29]. There are the defects of autonomous clock machinery in primary synovial cells isolated from rheumatoid arthritis (RA) patients [30]. This altered the synovial responsiveness to inflammatory cytokines during RA pathogenesis, suggesting the importance of the local clock. Furthermore, muscle-specific Bmall expression in Bmal1-null mice recovered the level of voluntary wheelrunning activity despite an arrhythmic pattern [31]. In our studies, the BMAL1 level at the same time of day differed in cartilage, synovium, and skeletal muscle. Circadian Bmall expression is regulated by the orphan nuclear receptors RORA and REV-ERB $\alpha$, the differential activities of which determine the tissue-specific BMAL1 level. Rev-erb $\alpha$ expressed rhythmically in most metabolic tissues, whereas Rora expression is non-rhythmic [32]. The tissue-dependent BMAL1 level might be induced by the differential Rora expression, but further experiments are needed to identify the mechanisms involved.

Apart from regulation of Bmall, Per gene regulation is critical in terms of joint homeostasis [33]. PER1 and PER2 co-operatively prevent the period length from oscillating to an extent $>24 \mathrm{~h}$ [34]. However, tissuespecific differences in Per gene expression are evident in peripheral organs, the circadian periods of which thus vary. Perl rhythmicity and the role played by such variation have been explored only in the synovium [35]. Per2 gene expression is rhythmic in cartilage [5], the synovium [35], and skeletal muscle [36]. Thus, we analyzed Per 1 and/or Per 2 gene expression in different tissues. The PER proteins are rhythmically expressed in the nuclei of normal synovial cells, but the levels differed (at the time of sacrifice) in cells of the vehicle- and melatonin-treated groups. The Per mRNA level peaked at approximately the ZT12 timepoint in the murine limbs, and decreased thereafter [37]. The PER protein should be located in nuclei at ZT14 (the time of sacrifice) because nuclear PER protein inhibits its own transcription. We found that the levels of nuclear PER 1/2 protein were lower in the vehicle- and melatonin-treated groups than in the control group. The BMAL1 protein levels were higher in the former two groups, indicating that circadian phaseshifting might be in play. In fact, melatonin advances the phase of the circadian rhythm in rats with chronic inflammation [38]. RANKL (encoded by Tnfsf11) is a clock-controlled gene involved in bone metabolism, and also plays a role in circadian regulation $[39,40]$. Thus, the observed phase-shifting may be attributable to melatonin 
(a)

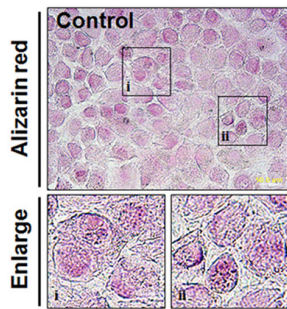

(b)

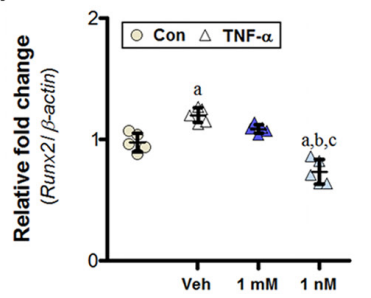

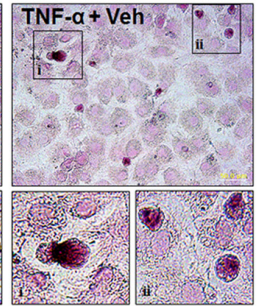

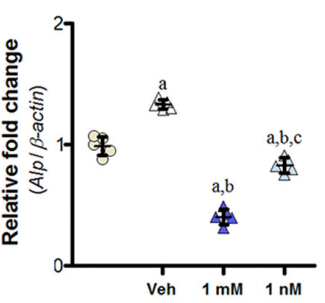

(c)

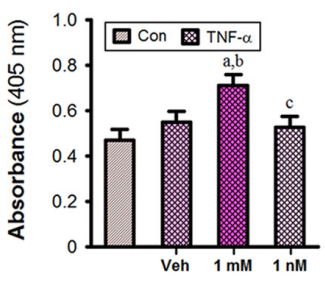

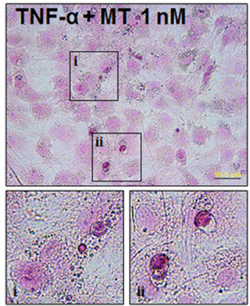

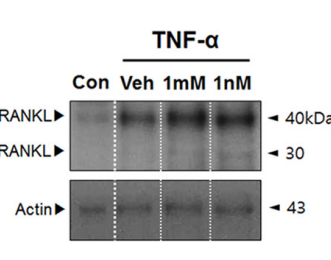

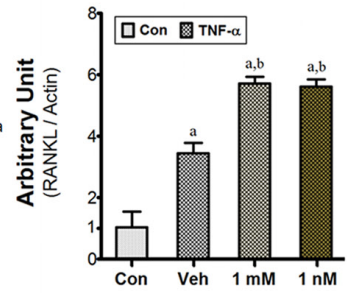

B

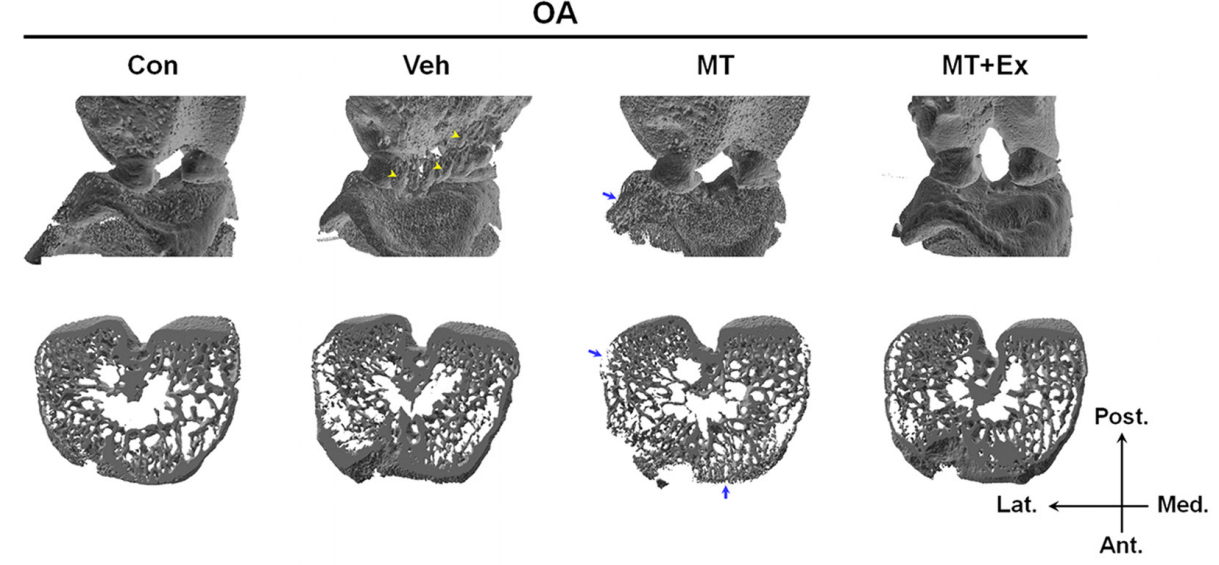

C

(a)

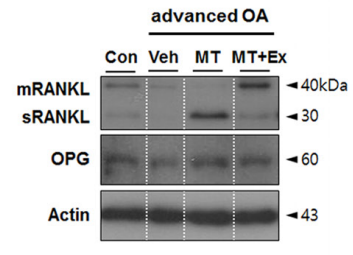

(b)

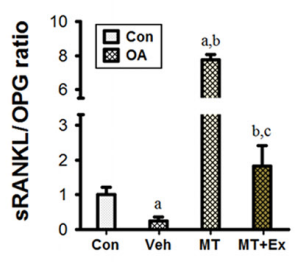

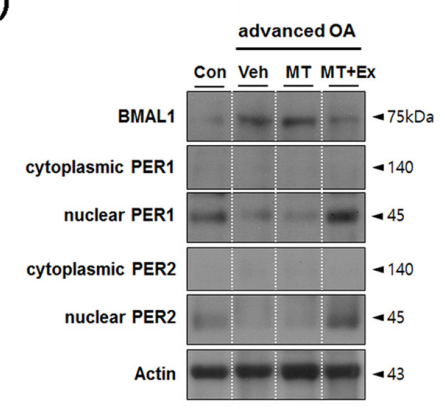

Figure 3: Melatonin combined with exercise maintains bone homeostasis in the advanced $\mathrm{OA}$ joint. A. (a) $\mathrm{Ca}^{2+}$ levels were measured by Alizarin red staining; high absorbance was observed in the $1 \mathrm{mM}$ melatonin-treated group. Magnification $\times 40$, scale bars $=50 \mu \mathrm{m}$. (b) Repeated inflammatory stimuli increased the expression of hypertrophic markers (Runx2, Alp) and (c) the level of RANKL. Melatonin treatment suppressed the hypertrophic changes despite higher levels of RANKL protein. ${ }^{\mathrm{a}} P<0.05$, $v s$. Con, ${ }^{\mathrm{b}} P<0.05, v s$. DMSO-Veh, ${ }^{c} P<0.05, v s .1 \mathrm{mM}$ MT. B. Reconstructed micro-CT images showing anterior view (upper panel) and horizontal cross section (lower panel). Yellow arrowhead, calcified tissue; blue arrow, bone erosion. C. (a) Immunoblot analysis showed that factors involved in bone remodeling processes were also detected in synovial membranes. Prolonged melatonin administration promoted the conversion of membrane-bound protein (mRANKL) to the soluble form (sRANKL), leading to a marked increase in the sRANKL:OPG ratio in the synovium. (b) The levels of core clock proteins (BMAL1, PER1, and PER2) were abnormally altered in both the vehicle and the melatonintreated groups, but combined intervention prevented this. ${ }^{a} P<0.05, v s$. Con, ${ }^{b} P<0.05, v s$. OA+Veh, ${ }^{c} P<0.05, v s$. OA+MT. 
treatment. We applied forced exercise at ZT15; nocturnal rodents commence physical activity at approximately ZT12 [41]. This additional intervention may have reset the local synovial time, allowing bone erosion to recover. Moreover, most RANKL protein was in soluble form in the synovium of the melatonin-treated group, indicating that membrane-bound RANKL may be cleaved by intraarticular MMPs [42]. In turn, this indicates the presence of synovial inflammation in the melatonin-treated group, although melatonin reduced $M m p 13$ gene expression in cartilage specimens. However, forced exercise inhibited the synovial inflammatory responses. We observed that the core clock components of skeletal muscle and arthritic joint (the cartilage and synovium) were both dysregulated, perhaps disrupting, in turn, metabolic balance of musculoskeletal tissue. These findings suggest that joint homeostasis is maintained by systemic regulation of peripheral clocks located in cartilage, the synovium, and skeletal muscle (Figure 5). Therefore, we suggest that the anti-arthritic effect of melatonin is determined by several factors, including the dose, treatment duration, combined exercise, and the time of initial intervention.

The COL2A1 protein and Col2al mRNA levels were inconsistent in the vehicle-treated group.
Inflammatory signals reduced chondrocyte Col2al mRNA levels and mRNA stability; our results are consistent with those of a previous study [43]. However, regulation at the protein level is more complicated than that at the mRNA level. Type II collagen is abnormally degraded by active MMPs (principally MMP-13) distributed over the entire joint during the early-to-intermediate phase of OA [44], leading to thinning of the surface cartilage. Pro-MMPs activation is inhibited by natural materials (tissue inhibitors of matrix metalloproteinases; TIMPs). Although the cartilage TIMP levels were reduced at the most advanced stages of disease, their concentrations were higher in synovial fluid [44, 45]. Thus, synovial MMPs are barely active in advanced-stage OA tissue, thus increasing the collagen level.

We found that melatonin at a high concentration (1 $\mathrm{mM}$ ) altered the cellular phenotype compared with that of the vehicle-treated group. Melatonin binds to calmodulin with low affinity, triggering ROS induction [46]. Excessive ROS activate the stress-induced kinase JNK [47], in turn upregulation of Epas 1 expression. HIF-2 $\alpha$ (encoded by the Epas1 gene) increased the cartilage expression levels of matrix catabolic enzymes [48]. The quantitative extent of Alcian blue staining was lower in the vehicle- and $1 \mathrm{mM}$

A

(a)

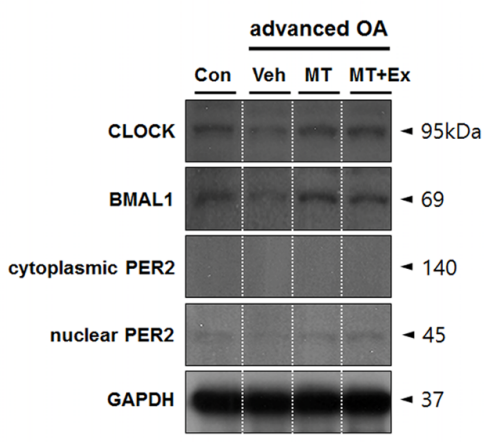

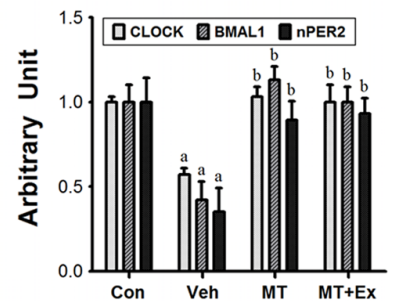

(b)

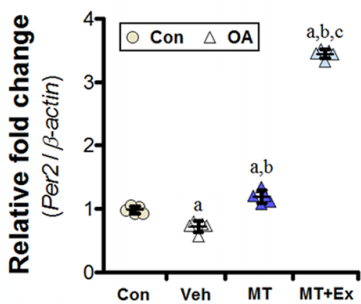

B
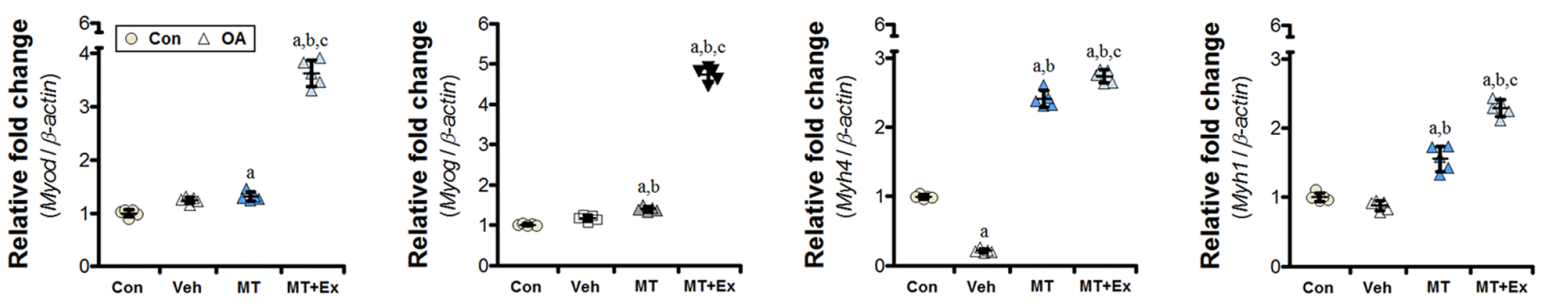

Figure 4: The preventive effects of melatonin with or without exercise on indirect muscular damage. A. (a) Intramuscular CLOCK, BMAL1, and PER2 levels were analyzed by immunoblotting, (b) and the expression of the clock gene Per2 was measured by real-time qPCR. The intra-articular inflammatory environment disrupted the expression of core clock proteins in the gastrocnemius, but melatonin and/or exercise restored those levels. B. The inflammatory joint altered expression of a gene associated with muscle fiber properties (Myh4). Melatonin treatment with or without exercise upregulated the expression of myogenic regulatory factors (Myod, Myog) and myosin heavy chain isoforms $(M y h 1, M y h 4)$. Data were normalized to $\beta$-actin. ${ }^{a} P<0.05, v s$. Con, ${ }^{b} P<0.05, v s$. OA+Veh, ${ }^{c} P<0.05$, vs. OA+MT. 
melatonin-treated cells than in the control cells, indicating that the glycosaminoglycan dynamics may be abnormal in both groups. The expression levels of Adamts4/9 genes were increased in the vehicle-treated group, reflecting the major roles played by these genes in severe proteoglycan loss. The levels of both MMP-13 protein and the encoding mRNA were increased in $1 \mathrm{mM}$ melatonin-treated cells, although the expression levels of the Adamts genes were unchanged. The ADAMTS proteins are involved in proteoglycan breakdown, but membrane-bound MMP13 and/or the cytoplasmic form degrade small amounts of proteoglycan in arthritic cartilage specimens [49]. High-dose melatonin enhanced cytoplasmic MMP-13 localization, triggering minor proteoglycan degradation. Melatonin at the $5 \sim 10 \mathrm{mg} / \mathrm{kg}$ of body weight in animals is known to potentially inhibit MMP activity [50, 51], but the chondrocyte effects that we observed were triggered by nanomolar melatonin, which inhibited both the cytonuclear shift of MMP-13 and protein activity. In contrast, MMP-13 was located predominantly in the nuclei of chondrocytes treated with TNF- $\alpha$. MMP13 bears a putative nuclear localization sequence [52], which may explain how MMP-13 becomes transported into the nucleus. MMP-13 was evident in the nuclei of both osteoarthritic chondrocytes and the normal cells [53]. Intranuclear MMP13 promotes the expression of the Ccn2/Ctgf genes of chondrocytes, triggering both ECM and cellular proliferation [54]. However, MMPs have been located in cell nuclei under certain pathological conditions (i.e., osteoarthritis, ischemic stroke, and tumors), wherein the MMPs degrade proteins involved in DNA repair and/or transcriptional regulation [55]. Further studies are required to assess whether the intracellular distribution of MMP-13 is associated with disruption of the biological clock.

These insufficient effects of melatonin were blocked by intervention combined with exercise. Although daily strenuous exercise might induce OA [56], low-impact exercise is beneficial [57]. Therefore, moderate exercise could be useful for decreasing the detrimental effects of melatonin at high dose or for the long-term. In fact, the serum TNF- $\alpha$ concentration was reduced to a greater extent with co-treatment. And combined intervention reinforced the myogenic ability as well as the contractile characteristics of muscle fibers through regulation of the local muscular clock. Myod is a muscle-specific clock-controlled gene [36], an increase in which may be mediated by recovery of core clock proteins. Changes in musculoskeletal units can alter biomechanical properties [58]. Weight-bearing is a feasible means by which to evaluate OA progression [59]; weight-bearing improved when the two interventions were applied. Thus, we suggest that a combination of melatonin treatment and exercise may exert regenerative effects on the cartilage, synovium, and muscles of patients with advanced OA.

\section{Musculoskeletal system}
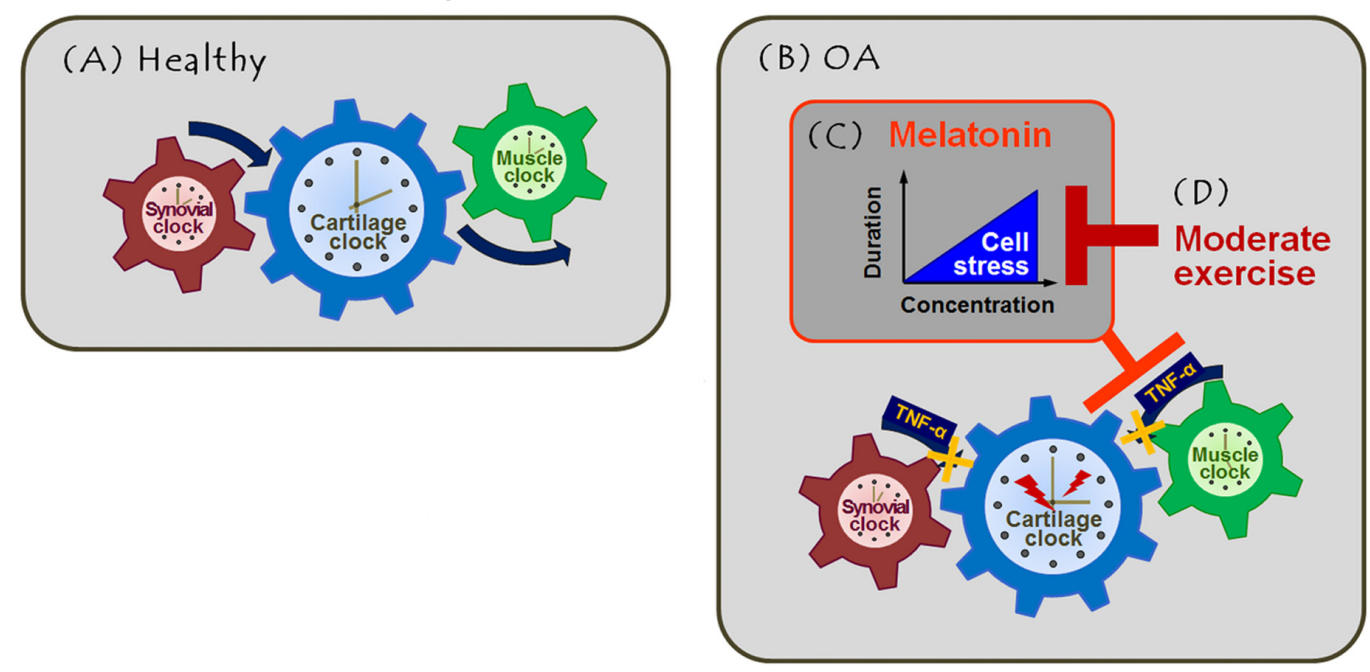

Figure 5: Melatonin combined with exercise rescues the articulomuscular axis injured in knee OA. A. Local clock systems regulated by the rhythmic expression of genes and proteins are present in healthy joint tissues (cartilage, synovium, and skeletal muscle), co-acting as three cog wheels. This maintains musculoskeletal homeostasis, possibly facilitating coordinated motion. B. The arthritic joint amplifies inflammatory signals (e.g., TNF- $\alpha$ ), leading to failure of engagement by the tissue-specific clocks. This causes dysregulation of the clock and clock-controlled molecules, which may impair daily activities. C. Melatonin at physiological concentrations effectively functioned as both an anti-inflammatory agent and an anti-oxidant in OA joints. However, melatonin damaged cells when given at high doses or long-term. D. The deleterious effects of melatonin were inhibited by combining melatonin intervention with moderate exercise. This regime suppressed the development of aberrant axial changes by regulating expression of the clock and clock-controlled proteins of the musculoskeletal unit. 
Table 2: Oligonucleotide primers used for PCR

\begin{tabular}{|c|c|c|c|}
\hline Gene & Primer sequence (5'-3') & Size (bp) & GenBank Accession No. \\
\hline Actb & $\begin{array}{l}\text { F: taa aga cet cta tgc caa cac agt } \\
\text { R: cac gat gga ggg gcc gga ctc atc }\end{array}$ & 241 & NM_031144.2 \\
\hline \multicolumn{4}{|c|}{ Anabolic activity-related genes } \\
\hline Col2al & $\begin{array}{l}\text { F: atg aca atc tgg ctc cca aca ctg c } \\
\text { R: gac cgg ccc tat gtc cac acc gaa t }\end{array}$ & 364 & {$[62]$} \\
\hline Sox9 & $\begin{array}{l}\text { F: aca acg caa gct tct gca ag } \\
\text { R: aca ctc tcc aac cac agc ag }\end{array}$ & 111 & NM_080403.1 \\
\hline $\operatorname{Tg} f \beta 1$ & $\begin{array}{l}\text { F: ata cgc ctg agt ggc tgt ct } \\
\text { R: tgg gac tga tcc cat tga tt }\end{array}$ & 153 & NM_021578.2 \\
\hline \multicolumn{4}{|c|}{ Catabolic activity-related genes } \\
\hline$A L P$ & $\begin{array}{l}\text { F: cct aga cac aag cac tcc cac ta } \\
\text { R: gtc agt cag gtt gtt ccg att c }\end{array}$ & 138 & NM_013059.1 \\
\hline Adamts4 & $\begin{array}{l}\text { F: agc ctt taa gca tcc aag ca } \\
\text { R: gga ggg ttt agg cct ttc tg }\end{array}$ & 153 & NM_023959.1 \\
\hline Adamts 9 & $\begin{array}{l}\text { F: gtg gct ctg tac tga agg agc } \\
\text { R: ccg tct cat atg get tcc tct }\end{array}$ & 153 & NM_001107877.1 \\
\hline Mmp13 & $\begin{array}{l}\text { F: agg cet tca gaa aag cet tc } \\
\text { R: gag ctg ctt gtc cag gtt tc }\end{array}$ & 226 & NM_133530.1 \\
\hline Mmpl4 & $\begin{array}{l}\text { F: agg gac cct cat agc ttg gt } \\
\text { R: tag ggc tca tat gcc caa ag }\end{array}$ & 190 & NM_031056.1 \\
\hline Runx2 & $\begin{array}{l}\text { F: gcc agg ttc aac gat ctg ag } \\
\text { R: gag gcg gtc aga gaa caa ac }\end{array}$ & 201 & NM_053470.2 \\
\hline $\operatorname{Vegf}$ & $\begin{array}{l}\text { F: gcc tca gga cat ggc act at } \\
\text { R: gga gga gga gga gcc att ac }\end{array}$ & 206 & NM_031836.2 \\
\hline \multicolumn{4}{|c|}{ Circadian clock genes } \\
\hline Bmal1 & $\begin{array}{l}\text { F: gtc gaa tga ttg ccg agg aa } \\
\text { R: ggg agg cgt act tgt gat gtt c }\end{array}$ & 101 & AB015203 \\
\hline Cryl & $\begin{array}{l}\text { F: ctt cca acg tgg gca tca ac } \\
\text { R: ccg aat cac aaa cag acg aga a }\end{array}$ & 101 & NM_007771.3 \\
\hline Perl & $\begin{array}{l}\text { F: ttt gga gag ctg caa cat tcc } \\
\text { R: ctg ccc tct get tgt cat ca }\end{array}$ & 101 & NM_011065.4 \\
\hline Per2 & $\begin{array}{l}\text { F: ggc tgt gtc cct ggt ttc tg } \\
\text { R: cca caa act tgg cat cac tga }\end{array}$ & 101 & NM_031678.1 \\
\hline \multicolumn{4}{|c|}{ Muscle-specific genes } \\
\hline Myh1 & $\begin{array}{l}\text { F: acg gtc gaa gtt gca tcc cta aag } \\
\text { R: cac ctt cgg tct tgg ctg tca c }\end{array}$ & 263 & NM_001135158.1 \\
\hline Myh4 & $\begin{array}{l}\text { F: agc ctg cct cct tct tca tct gg } \\
\text { R: cac ggt tgc ttt cac ata gga ctc }\end{array}$ & 229 & NM_019325.1 \\
\hline Myod & $\begin{array}{l}\text { F: agc ata gtg gag cgc atc t } \\
\text { R: gtt ctg cat cgc ttg agg a }\end{array}$ & 118 & NM_176079.1 \\
\hline Myog & $\begin{array}{l}\text { F: tcc cag atg aaa cca tgc cc } \\
\text { R: cca ctt aaa agg ccc ctg ct }\end{array}$ & 111 & NM_017115.2 \\
\hline
\end{tabular}




\section{MATERIALS AND METHODS}

\section{Induction of advanced osteoarthritis and intervention}

Male Sprague Dawley rats (8-week-old, $n=32$ ) were used. Rats were housed under artificial light-dark conditions at a controlled temperature, and ZT0 was set at 07:00. All rats were provided with water and food ad libitum. Experimental procedures were approved by the Ethics Committee for Animal Care and Use at Inje University (approval no. 2010-72). Experimental OA was induced by knee instability via intra-articular collagenase injection in the right knee [14]. At 4 weeks after injection, the degree of gait disturbance was used as a criterion for moderate-to-severe OA. The interventional protocol was described previously [14], and the period was a further 4 weeks (Figure 1A). The rats were given $10 \mathrm{mg} / \mathrm{kg}$ melatonin twice daily. Those with moderate-to-severe OA were exercised on a motor-driven treadmill without inclination at $11 \mathrm{~m} / \mathrm{min}$, for $30 \mathrm{~min} /$ day at ZT15, for 5 consecutive days. Experimental rats were divided into four groups ( $n=8$ for each condition): control (Con), OA with no intervention $(\mathrm{OA}+\mathrm{Veh}), \mathrm{OA}$ with melatonin treatment alone $(\mathrm{OA}+\mathrm{MT})$, and $\mathrm{OA}$ with melatonin treatment and moderate treadmill exercise $(\mathrm{OA}+\mathrm{MT}+\mathrm{Ex})$. After sacrifice, specimens were excised at ZT14, snap-frozen in liquid nitrogen, and stored at $-80^{\circ} \mathrm{C}$.

\section{Footprint measurements}

Footprint analyses were performed as described previously [60]. We measured the linear distance between a print of the right paw and a consecutive print of the left paw (right-left). Each distance was normalized with the mean value of the control rats, represented as \% linear distance.

\section{Serum TNF- $\alpha$ measurement}

Serum was stored at $-80^{\circ} \mathrm{C}$ until analysis, then thawed, and run in duplicate. TNF- $\alpha$ levels were quantified using an ELISA kit (eBioscience, San Diego, CA, USA). Immunoassay results were then read with a fluorescence multi-detection reader (Bio-Tek Instruments, Winooski, VT, USA) at 620 and $450 \mathrm{~nm}$. The concentrations were quantitated using the GraphPad PRISM software (ver. 5.0; GraphPad Software, La Jolla, CA, USA). A nonlinear regression analysis was used to derive an equation to predict the concentration in unknown samples.

\section{Histomorphological assessments}

Micro-computed tomography (micro-CT) was used to assess OA-induced skeletal deformations, as described previously [14]. After scanning the limbs, we created 3D models of the lesional knee joints. And then we analyzed the quantitative values using manufacture's software. For histological analyses, tissues were fixed in $4 \%$ neutral buffered paraformaldehyde ( $\mathrm{pH}$ 7.4). Specimens were decalcified with $368 \mathrm{mM}$ EDTA (pH 7.4). Cryosectioning was performed using a cryostat microtome (MICROM International $\mathrm{GmbH}$, Walldorf, Germany). Hematoxylin and eosin (Sigma-Aldrich, St. Louis, MO, USA)stained images were analyzed using an Olympus DP70 microscope, using a $20 \times$ objective and digital camera (Olympus, Tokyo, Japan) connected to a computer.

\section{Cell culture}

Chondrocytes were isolated from the tibial plateau of neonatal rats. At 7 days of culture, the intrinsic clock was reset with serum shock before stimulation with TNF- $\alpha$. Medium was replaced with DMEM including 50\% fetal bovine serum (FBS; Hyclone, Logan, UT, USA) and $1 \%$ penicillin/streptomycin (Lonza, Walkersville, MD, USA). After $2 \mathrm{~h}$, the medium was replaced with DMEM containing $1 \%$ FBS and antibiotics. Then, recombinant TNF- $\alpha(10 \mathrm{ng} / \mathrm{mL})$ was added repeatedly to the medium, three times at 4-h intervals (Figure 2A, c). We then treated twice with melatonin $(1 \mathrm{mM}, 1 \mathrm{nM})$. Melatonin (SigmaAldrich) was dissolved in dimethyl sulfoxide (DMSO; Bio Basic Inc., Amherst, NY, USA). The final concentration of DMSO in culture medium did not exceed $0.1 \%$, which caused $<10 \%$ cytotoxicity versus untreated control cells.

\section{Alcian blue and alizarin red staining}

We performed Alcian blue staining to compare the amounts of GAGs in the chondrocytes. The dye was extracted with $4 \mathrm{M}$ guanidine- $\mathrm{HCl}$ (Sigma-Aldrich), and then measured at $620 \mathrm{~nm}$ [14]. Alizarin red, which indicates intracellular $\mathrm{Ca}^{2+}$ deposition, was quantified by extraction with $0.5 \mathrm{~N} \mathrm{HCl}$ and $5 \%$ sodium dodecyl sulfate (SDS) and then measured at $405 \mathrm{~nm}$ [61].

\section{Immunofluorescence}

Cells were washed, fixed with $4 \%$ paraformaldehyde, and incubated in $5 \%$ normal horse serum in $0.2 \%$ Triton PBS for $1 \mathrm{~h}$. A rabbit polyclonal anti-MMP-13 (Santa Cruz Biotechnology, Santa Cruz, CA, USA) was added to the cells overnight at $4{ }^{\circ} \mathrm{C}$. The cells were further incubated with a secondary antibody, CFL 488-conjugated goat antirabbit IgG (Santa Cruz Biotechnology), for $2 \mathrm{~h}$. The cells 
were then washed and mounted with Vectashield mounting medium with DAPI (Vector Laboratories Inc., Burlingame, CA, USA). The stained cells were examined using an Olympus BX51 microscope, using a $40 \times$ objective and software (Olympus). To examine the protein distribution, the proportion of MMP-13 localizing with or without DAPI in the cells was quantified using ImageJ ver. 1.48 (NIH, Bethesda, MD, USA).

\section{Quantitative real-time RT-PCR}

RNA was isolated from the specimens using the TRI-reagent (Sigma-Aldrich). RNA (1 $\mu \mathrm{g})$ was reversetranscribed using reverse transcriptase (Invitrogen, Carlsbad, CA, USA). The cDNA was amplified with specific primers (Table 2). Each PCR was processed in triplicate. For quantitative real-time PCR, reactions were monitored using a Light Cycler 1.5 (Roche Instrument Center AG, Rotkreuz, Switzerland) with LightCycler FastStart DNA Master SYBR Green I. The $C_{\mathrm{t}}$ value of $\beta$-actin was subtracted from that of the target gene $\left(\Delta C_{\mathrm{t}}\right)$, and the average $\Delta C_{t}$ value of the triplicate samples was recorded. The relative gene expression in OA rats versus that in control animals was calculated using the $2^{-\Delta \Delta C t}$ method.

\section{Protein extraction and Western blotting}

Specimens were lysed in a buffer supplemented with a protease inhibitor cocktail (Roche) [14]. Concentrations of proteins were measured with the Bradford assay (Bio-Rad Laboratories, Richmond, CA, USA) using a spectrophotometer. Proteins $(20 \mu \mathrm{g})$ were separated by SDS-PAGE and transferred to a PVDF membrane (Merck Millipore, Billerica, MA, USA). The following primary antibodies were incubated overnight with the blocked membranes: rabbit polyclonal anti-COL2A1, rabbit polyclonal anti-MMP-13 (Santa Cruz Biotechnology), goat polyclonal anti-BMAL1, goat polyclonal antiCLOCK, rabbit polyclonal anti-OPG, goat polyclonal anti-PER1, goat polyclonal anti-PER2, goat polyclonal anti-RANKL, mouse monoclonal anti-actin, rabbit polyclonal anti-GAPDH, and rabbit monoclonal anticleaved caspase-3 (Cell Signaling Technology, Danvers, MA, USA). Membranes were then incubated with the secondary antibody. Finally, specific bands were visualized with chemiluminescent reagents (Pierce Biotechnology, Rockford, IL, USA) and quantified using the ImageJ software.

\section{Statistical analyses}

Data are presented as means \pm SD. Significance was determined using one-way analysis of variance with a post hoc Tukey test. Differences were considered to be significant at $P<0.05$. All analyses were performed using the SPSS software (ver. 20.0; IBM, New York, NY, USA).

\section{Abbreviations}

ECM-Extracellular matrix; GAGsGlycosaminoglycans; H\&E-Hematoxylin and Eosin; OAOsteoarthritis; RA-Rheumatoid arthritis; ROS-Reactive oxygen species; TIMP-Tissue inhibitors of matrix metalloproteinases.

\section{Author contributions}

This study was conceptualized and designed by Yonggeun Hong, Yunkyung Hong and Kyu-Tae Chang. Yunkyung Hong, Hyunsoo Kim and Seunghoon Lee performed most of the experiments with assistance from Yunho Jin and Jeonghyun Choi. Yonggeun Hong, Kyu-Tae Chang and Sang-Rae Lee supervised the study. Yonggeun Hong and Yunkyung Hong wrote the manuscript. All authors commented on the manuscript and approved the final form of manuscript.

\section{ACKNOWLEDGMENTS}

We thank Sookyoung Park, Jinyoung Won, Sungho Kwon and Sungjoon Oh for critical reading for the manuscript, Joo-Heon Kim and Jongwon Kim for helpful suggestions and useful discussions.

\section{CONFLICTS OF INTEREST}

The authors declare no conflict of interest.

\section{FUNDING}

This work was supported by grants from the National Research Foundation (NRF-2013R1A2A2A01067169 to Y.H., NRF-2015R1C1A2A01055691 to Y.H.), and by the KRIBB Research Initiative Program (KGM4611714), Republic of Korea. This work was also supported by the 2016 creative research program of Inje University. Y.H. and S.L. in leading authors are supported by the Postdoctoral Research Program of Inje University.

\section{REFERENCES}

1. van der Kraan PM, Blaney Davidson EN, Blom A, van den Berg WB. TGF-beta signaling in chondrocyte terminal differentiation and osteoarthritis: modulation and integration of signaling pathways through receptor-Smads. Osteoarthritis Cartilage. 2009; 17:1539-1545.

2. Magne D, Bluteau G, Faucheux C, Palmer G, Vignes- 
Colombeix C, Pilet P, Rouillon T, Caverzasio J, Weiss P, Daculsi G, Guicheux J. Phosphate is a specific signal for ATDC5 chondrocyte maturation and apoptosis-associated mineralization: possible implication of apoptosis in the regulation of endochondral ossification. J Bone Miner Res. 2003; 18:1430-1442.

3. Fuerst M, Lammers L, Schafer F, Niggemeyer O, Steinhagen J, Lohmann $\mathrm{CH}$, Ruther W. Investigation of calcium crystals in OA knees. Rheumatol Int. 2010; 30:623631.

4. Bellamy N, Sothern RB, Campbell J, Buchanan WW. Rhythmic variations in pain, stiffness, and manual dexterity in hand osteoarthritis. Ann Rheum Dis. 2002; 61:10751080 .

5. Gossan N, Zeef L, Hensman J, Hughes A, Bateman JF, Rowley L, Little CB, Piggins HD, Rattray M, BootHandford RP, Meng QJ. The circadian clock in murine chondrocytes regulates genes controlling key aspects of cartilage homeostasis. Arthritis Rheum. 2013; 65:23342345.

6. Dudek M, Gossan N, Yang N, Im HJ, Ruckshanthi JP, Yoshitane H, Li X, Jin D, Wang P, Boudiffa M, Bellantuono I, Fukada Y, Boot-Handford RP, et al. The chondrocyte clock gene Bmall controls cartilage homeostasis and integrity. J Clin Invest. 2016; 126:365-376.

7. Vriend J, Reiter RJ. Melatonin feedback on clock genes: a theory involving the proteasome. J Pineal Res. 2015; 58:111.

8. Aoyama S, Shibata S. The Role of Circadian Rhythms in Muscular and Osseous Physiology and Their Regulation by Nutrition and Exercise. Front Neurosci. 2017; 11:63.

9. Mishima K, Okawa M, Hozumi S, Hishikawa Y. Supplementary administration of artificial bright light and melatonin as potent treatment for disorganized circadian rest-activity and dysfunctional autonomic and neuroendocrine systems in institutionalized demented elderly persons. Chronobiol Int. 2000; 17:419-432.

10. Manchester LC, Coto-Montes A, Boga JA, Andersen LP, Zhou Z, Galano A, Vriend J, Tan DX, Reiter RJ. Melatonin: an ancient molecule that makes oxygen metabolically tolerable. J Pineal Res. 2015; 59:403-419.

11. Reiter RJ, Mayo JC, Tan DX, Sainz RM, Alatorre-Jimenez M, Qin L. Melatonin as an antioxidant: under promises but over delivers. J Pineal Res. 2016; 61:253-278.

12. Lin GJ, Huang SH, Chen SJ, Wang CH, Chang DM, Sytwu HK. Modulation by melatonin of the pathogenesis of inflammatory autoimmune diseases. Int J Mol Sci. 2013; 14:11742-11766.

13. Zhang HM, Zhang Y. Melatonin: a well-documented antioxidant with conditional pro-oxidant actions. J Pineal Res. 2014; 57:131-146.

14. Hong Y, Kim H, Lee Y, Lee S, Kim K, Jin Y, Lee SR, Chang KT, Hong Y. Salutary effects of melatonin combined with treadmill exercise on cartilage damage. J Pineal Res.
2014; 57:53-66.

15. Galois L, Etienne S, Grossin L, Watrin-Pinzano A, Cournil-Henrionnet C, Loeuille D, Netter P, Mainard D, Gillet P. Dose-response relationship for exercise on severity of experimental osteoarthritis in rats: a pilot study. Osteoarthritis Cartilage. 2004; 12:779-786.

16. Gomes WF, Lacerda AC, Mendonca VA, Arrieiro AN, Fonseca SF, Amorim MR, Rocha-Vieira E, Teixeira AL, Teixeira MM, Miranda AS, Coimbra CC, Brito-Melo GE. Effect of aerobic training on plasma cytokines and soluble receptors in elderly women with knee osteoarthritis, in response to acute exercise. Clin Rheumatol. 2012; 31:759766.

17. Madhavan S, Anghelina M, Rath-Deschner B, Wypasek E, John A, Deschner J, Piesco N, Agarwal S. Biomechanical signals exert sustained attenuation of proinflammatory gene induction in articular chondrocytes. Osteoarthritis and cartilage. 2006; 14:1023-1032.

18. Sellam J, Berenbaum F. The role of synovitis in pathophysiology and clinical symptoms of osteoarthritis. Nat Rev Rheumatol. 2010; 6:625-635.

19. Danks L, Komatsu N, Guerrini MM, Sawa S, Armaka M, Kollias G, Nakashima T, Takayanagi H. RANKL expressed on synovial fibroblasts is primarily responsible for bone erosions during joint inflammation. Ann Rheum Dis. 2016; 75:1187-1195.

20. Reid MB, Moylan JS. Beyond atrophy: redox mechanisms of muscle dysfunction in chronic inflammatory disease. J Physiol. 2011; 589:2171-2179.

21. Madden RM, Han SK, Herzog W. The effect of compressive loading magnitude on in situ chondrocyte calcium signaling. Biomech Model Mechanobiol. 2015; 14:135-142.

22. Talmadge RJ, Roy RR. Electrophoretic separation of rat skeletal muscle myosin heavy-chain isoforms. J Appl Physiol. 1993; 75:2337-2340.

23. Qvist P, Bay-Jensen AC, Christiansen C, Dam EB, Pastoureau P, Karsdal MA. The disease modifying osteoarthritis drug (DMOAD): Is it in the horizon? Pharmacol Res. 2008; 58:1-7.

24. ter Huurne M, Schelbergen R, Blattes R, Blom A, de Munter W, Grevers LC, Jeanson J, Noel D, Casteilla L, Jorgensen C, van den Berg W, van Lent PL. Antiinflammatory and chondroprotective effects of intraarticular injection of adipose-derived stem cells in experimental osteoarthritis. Arthritis Rheum. 2012; 64:3604-3613.

25. Escames G, Ozturk G, Bano-Otalora B, Pozo MJ, Madrid JA, Reiter RJ, Serrano E, Concepcion M, Acuna-Castroviejo D. Exercise and melatonin in humans: reciprocal benefits. $J$ Pineal Res. 2012; 52:1-11.

26. Buxton OM, L'Hermite-Baleriaux M, Hirschfeld U, Cauter E. Acute and delayed effects of exercise on human melatonin secretion. J Biol Rhythms. 1997; 12:568-574.

27. Miyazaki T, Hashimoto S, Masubuchi S, Honma S, Honma KI. Phase-advance shifts of human circadian pacemaker 
are accelerated by daytime physical exercise. Am J Physiol Regul Integr Comp Physiol. 2001; 281:R197-205.

28. Barger LK, Wright KP Jr, Hughes RJ, Czeisler CA. Daily exercise facilitates phase delays of circadian melatonin rhythm in very dim light. Am J Physiol Regul Integr Comp Physiol. 2004; 286:R1077-1084.

29. Bunger MK, Walisser JA, Sullivan R, Manley PA, Moran SM, Kalscheur VL, Colman RJ, Bradfield CA. Progressive arthropathy in mice with a targeted disruption of the Mop3/ Bmal-1 locus. Genesis. 2005; 41:122-132.

30. Kouri VP, Olkkonen J, Kaivosoja E, Ainola M, Juhila J, Hovatta I, Konttinen YT, Mandelin J. Circadian timekeeping is disturbed in rheumatoid arthritis at molecular level. PloS one. 2013; 8:e54049.

31. McDearmon EL, Patel KN, Ko CH, Walisser JA, Schook AC, Chong JL, Wilsbacher LD, Song EJ, Hong HK, Bradfield CA, Takahashi JS. Dissecting the functions of the mammalian clock protein BMAL1 by tissue-specific rescue in mice. Science. 2006; 314:1304-1308.

32. Yang X, Downes M, Yu RT, Bookout AL, He W, Straume M, Mangelsdorf DJ, Evans RM. Nuclear receptor expression links the circadian clock to metabolism. Cell. 2006; 126:801-810.

33. Fu L, Patel MS, Bradley A, Wagner EF, Karsenty G. The molecular clock mediates leptin-regulated bone formation. Cell. 2005; 122:803-815.

34. Tamiya H, Ogawa S, Ouchi Y, Akishita M. Rigid Cooperation of Per1 and Per2 proteins. Sci Rep. 2016; 6:32769.

35. Becker T, Tohidast-Akrad M, Humpeler S, Gerlag DM, Kiener HP, Zenz P, Steiner G, Ekmekcioglu C. Clock gene expression in different synovial cells of patients with rheumatoid arthritis and osteoarthritis. Acta Histochem. 2014; 116:1199-1207.

36. McCarthy JJ, Andrews JL, McDearmon EL, Campbell KS, Barber BK, Miller BH, Walker JR, Hogenesch JB, Takahashi JS, Esser KA. Identification of the circadian transcriptome in adult mouse skeletal muscle. Physiol Genomics. 2007; 31:86-95.

37. Hand LE, Hopwood TW, Dickson SH, Walker AL, Loudon AS, Ray DW, Bechtold DA, Gibbs JE. The circadian clock regulates inflammatory arthritis. FASEB J. 2016; 30:37593770 .

38. Laste G, Vidor L, de Macedo IC, Rozisky JR, Medeiros L, de Souza A, Meurer L, de Souza IC, Torres IL, Caumo W. Melatonin treatment entrains the rest-activity circadian rhythm in rats with chronic inflammation. Chronobiol Int. 2013; 30:1077-1088.

39. Hirai T, Tanaka K, Togari A. alpha1B-Adrenergic receptor signaling controls circadian expression of Tnfrsfl $1 \mathrm{~b}$ by regulating clock genes in osteoblasts. Biol Open. 2015; 4:1400-1409.

40. Fujihara Y, Kondo H, Noguchi T, Togari A. Glucocorticoids mediate circadian timing in peripheral osteoclasts resulting in the circadian expression rhythm of osteoclast-related genes. Bone. 2014; 61:1-9.

41. Knight EM, Brown TM, Gumusgoz S, Smith JC, Waters EJ, Allan SM, Lawrence CB. Age-related changes in core body temperature and activity in triple-transgenic Alzheimer's disease (3xTgAD) mice. Dis Model Mech. 2013; 6:160170.

42. Nakashima T, Kobayashi Y, Yamasaki S, Kawakami A, Eguchi K, Sasaki H, Sakai H. Protein expression and functional difference of membrane-bound and soluble receptor activator of NF-kappaB ligand: modulation of the expression by osteotropic factors and cytokines. Biochem Biophys Res Commun. 2000; 275:768-775.

43. Seguin CA, Bernier SM. TNFalpha suppresses link protein and type II collagen expression in chondrocytes: Role of MEK1/2 and NF-kappaB signaling pathways. J Cell Physiol. 2003; 197:356-369.

44. Schmidt-Rohlfing B, Thomsen M, Niedhart C, Wirtz DC, Schneider U. Correlation of bone and cartilage markers in the synovial fluid with the degree of osteoarthritis. Rheumatol Int. 2002; 21:193-199.

45. Tchetverikov I, Lohmander LS, Verzijl N, Huizinga TW, TeKoppele JM, Hanemaaijer R, DeGroot J. MMP protein and activity levels in synovial fluid from patients with joint injury, inflammatory arthritis, and osteoarthritis. Ann Rheum Dis. 2005; 64:694-698.

46. Radogna F, Paternoster L, De Nicola M, Cerella C, Ammendola S, Bedini A, Tarzia G, Aquilano K, Ciriolo M, Ghibelli L. Rapid and transient stimulation of intracellular reactive oxygen species by melatonin in normal and tumor leukocytes. Toxicol Appl Pharmacol. 2009; 239:37-45.

47. Loeser RF. Aging and osteoarthritis: the role of chondrocyte senescence and aging changes in the cartilage matrix. Osteoarthritis Cartilage. 2009; 17:971-979.

48. Yang S, Kim J, Ryu JH, Oh H, Chun CH, Kim BJ, Min BH, Chun JS. Hypoxia-inducible factor-2alpha is a catabolic regulator of osteoarthritic cartilage destruction. Nat Med. 2010; 16:687-693.

49. Roughley PJ, Mort JS. The role of aggrecan in normal and osteoarthritic cartilage. J Exp Orthop. 2014; 1:8.

50. Tai SH, Chen HY, Lee EJ, Chen TY, Lin HW, Hung YC, Huang SY, Chen YH, Lee WT, Wu TS. Melatonin inhibits postischemic matrix metalloproteinase-9 (MMP9) activation via dual modulation of plasminogen/plasmin system and endogenous MMP inhibitor in mice subjected to transient focal cerebral ischemia. J Pineal Res. 2010; 49:332-341.

51. Esposito E, Genovese T, Caminiti R, Bramanti P, Meli R, Cuzzocrea $\mathrm{S}$. Melatonin regulates matrix metalloproteinases after traumatic experimental spinal cord injury. J Pineal Res. 2008; 45:149-156.

52. Kohrmann A, Kammerer U, Kapp M, Dietl J, Anacker J. Expression of matrix metalloproteinases (MMPs) in primary human breast cancer and breast cancer cell lines: New findings and review of the literature. BMC Cancer. 2009; 9:188. 
53. Woo YJ, Joo YB, Jung YO, Ju JH, Cho ML, Oh HJ, Jhun JY, Park MK, Park JS, Kang CM, Sung MS, Park SH, Kim HY, et al. Grape seed proanthocyanidin extract ameliorates monosodium iodoacetate-induced osteoarthritis. Exp Mol Med. 2011; 43:561-570.

54. Eguchi T, Kubota S, Kawata K, Mukudai Y, Uehara J, Ohgawara T, Ibaragi S, Sasaki A, Kuboki T, Takigawa M. Novel transcription-factor-like function of human matrix metalloproteinase 3 regulating the $\mathrm{CTGF} / \mathrm{CCN} 2$ gene. Mol Cell Biol. 2008; 28:2391-2413.

55. Mannello F, Medda V. Nuclear localization of matrix metalloproteinases. Prog Histochem Cytochem. 2012; 47:27-58.

56. Echtermeyer F, Bertrand J, Dreier R, Meinecke I, Neugebauer K, Fuerst M, Lee YJ, Song YW, Herzog C, Theilmeier G, Pap T. Syndecan-4 regulates ADAMTS-5 activation and cartilage breakdown in osteoarthritis. Nat Med. 2009; 15:1072-1076.

57. Cifuentes DJ, Rocha LG, Silva LA, Brito AC, RueffBarroso CR, Porto LC, Pinho RA. Decrease in oxidative stress and histological changes induced by physical exercise calibrated in rats with osteoarthritis induced by monosodium iodoacetate. Osteoarthritis Cartilage. 2010; 18:1088-1095.

58. Snedeker JG, Wirth SH, Espinosa N. Biomechanics of the normal and arthritic ankle joint. Foot Ankle Clin. 2012; 17:517-528
59. Bove SE, Calcaterra SL, Brooker RM, Huber CM, Guzman RE, Juneau PL, Schrier DJ, Kilgore KS. Weight bearing as a measure of disease progression and efficacy of antiinflammatory compounds in a model of monosodium iodoacetate-induced osteoarthritis. Osteoarthritis Cartilage. 2003; 11:821-830.

60. Hong Y, Kim JH, Jin Y, Lee S, Park K, Lee Y, Chang KT. Melatonin treatment combined with treadmill exercise accelerates muscular adaptation through early inhibition of CHOP-mediated autophagy in the gastrocnemius of rats with intra-articular collagenase-induced knee laxity. J Pineal Res. 2014; 56:175-188.

61. Pevsner-Fischer M, Morad V, Cohen-Sfady M, RoussoNoori L, Zanin-Zhorov A, Cohen S, Cohen IR, Zipori D. Toll-like receptors and their ligands control mesenchymal stem cell functions. Blood. 2007; 109:1422-1432.

62. Yoshimura H, Muneta T, Nimura A, Yokoyama A, Koga H, Sekiya I. Comparison of rat mesenchymal stem cells derived from bone marrow, synovium, periosteum, adipose tissue, and muscle. Cell Tissue Res. 2007; 327:449-462. 